\title{
When Students Struggle with Gross Anatomy and Histology: A Strategy for Monitoring, Reviewing, and Promoting Student Academic Success in an Integrated Preclinical Medical Curriculum
}

\author{
Michael Hortsch, ${ }^{1,3 *}$ Rajesh S. Mangrulkar ${ }^{2,3}$ \\ ${ }^{1}$ Department of Cell and Developmental Biology, University of Michigan Medical School, Ann Arbor, \\ Michigan \\ ${ }^{2}$ Department of Internal Medicine, University of Michigan Medical School, Ann Arbor, Michigan \\ ${ }^{3}$ Department of Learning Health Sciences, University of Michigan Medical School, Ann Arbor, Michigan
}

Gross anatomy and histology are now often taught as parts of an integrated medical or dental curriculum. Although this puts these foundational basic sciences into a wider educational context, students may not fully appreciate their importance as essential components of their medical education and may not develop a sufficient level of competency, as they are not stand-alone courses. The early identification of medical or dental students who struggle with anatomy or histology and the facilitation of adequate didactic support constitute a significant problem in an integrated curriculum. The timely intervention by an academic review board in combination with an individualized faculty-mediated counseling and remediation process may provide an effective solution to this problem. Anat Sci Educ 8: 478-483. @ 2015 American Association of Anatomists.

Key words: histology education; gross anatomy education; medical education; microscopic anatomy; medical curriculum; integrated curriculum; medical students; academic failure; academic remediation

\section{INTRODUCTION AND THE PROBLEM}

The structure of medical school curricula across North America has taken a few stereotypic forms, usually comprised of two years of preclinical courses, followed by two years of immersive clinical rotations (Cooke et al., 2006). Over the past 20 years, many schools have adopted a systems-based organization to the content for each preclinical course (e.g., cardiovascular pathophysiology, endocrine-based problems) (Drake et al., 2002, 2009, 2014; Heylings, 2002). While this architecture allows students to develop a deep understanding of a single system, it also presents a challenge of how to integrate core disciplines that apply to each system but are not stand-alone courses in this approach (Muller et al., 2008; Drake et al.,

\footnotetext{
${ }^{*}$ Correspondence to: Dr. Michael Hortsch, University of Michigan Medical School, 3761B Med. Sci. Building II, 1137 E. Catherine Street, Ann Arbor, MI 48109. E-mail: hortsch@umich.edu

Received 9 July 2014; Revised 11 November 2014; Accepted 23 December 2014.

Published online 16 January 2015 in Wiley Online Library (wileyonlinelibrary.com). DOI 10.1002/ase.1519

(c) 2015 American Association of Anatomists
}

2009; Abali et al., 2014). Many schools have experience with integrating a single pedagogical method or an approach that enhances the clinical relevance of the preclinical content (Donner and Bickley, 1993; Coppus et al., 2007; Scheffer et al., 2012). However, by dispersing content area such as anatomy and histology among different courses, the risk to student learning can be significant. First, learners separate their studying in time, possibly challenging their retention of facts because of prolonged time intervals. Second, students' motivation to learn an integrated discipline must compete with the motivation to engage in the organ system addressed in that course. Third, it is often difficult to assess which students may be struggling within the integrated discipline, because assessments are likewise dispersed with the content.

A few schools have used a combination of strategies to improve students' performance in medical school. These include (1) early identification of student factors that may increase academic risk, (2) monitoring of students' performance while in courses, (3) formal notification for academic deficiencies with structured remediation, and (4) recommended or mandated use of learning support resources by students who are at risk, struggling with coursework, or are experiencing academic deficiencies. More general tactics that many schools have used include addressing personal, social, 
and psychological stressors, engagement of trained longitudinal coaches or mentors, collaborative or individual development of goals and learning plans, and periodic tracking and monitoring of academic achievement (Durning et al., 2011; Audetat et al., 2013; Bearman et al., 2013; Cleland et al., 2013; McLaughlin et al., 2013; Stegers-Jager et al., 2013). These actions address some of the many reasons why students struggle in medical school, including lack of time management, limited basic science background, and inadequate study and test taking skills (Winston et al., 2010).

A review of the existing literature on this topic by Hauer et al. (2009) did not identify a single clear path toward effective remediation, but rather calls for a model involving "multiple assessment tools for identifying deficiencies, individualized instruction, deliberate practice followed by feedback and reflection, and reassessment." In addition, successful remediation at the medical school level appears to be positively correlated with teacher experience and active involvement (Winston et al., 2013). The remediation problem is further complicated as many current models only consider short-term, rather than long-term improvements of students' academic performance (Pell et al., 2012). The immediate successful completion of a failed examination or test often takes precedence over the general improvement of learning skills and approaches (Royal et al., 2014).

\section{Specific Challenges for Students Learning Anatomy and Histology}

Basic science subjects like anatomy and histology provide a foundation for clinical knowledge and are essential components of an integrated curriculum (Drake, 1998; Older, 2004; Klement et al., 2011). About half of all American schools continue to teach these subjects in separate, independent courses, but at others they are partially or fully integrated, usually within organ-based courses (Drake et al., 2014). This latter approach converts both anatomy and histology into longitudinal learning disciplines, threatening their didactic continuity by dispersing them among multiple courses. This change has been implicated in a decline in anatomical knowledge among students (McKeown et al., 2003). In addition, students might choose to spend more time studying other topics to pass an integrated course examination.

Few published studies address the problem of how to identify students at-risk of failing a preclinical course (Huff and Fang, 1999; Sadik and Rojas, 2014), specifically for anatomy or histology (Jones and Thomae-Forgues, 1984; Koenig, 1992; Lindblom-Ylänne et al., 1996; Forester et al., 2002; Selvig et al., 2015; Burns and Garrett, 2015). Relevant premedical education appears to be one important factor, as students with a biomedical science background and a related college degree and students with previous classroom experience in anatomy, histology or pathology are likely to do well in a corresponding medical school course (Koenig, 1992; Forester et al., 2002; Selvig et al., 2015). Performance in the anatomical sciences is also positively correlated with high premedical school entrance examination scores (Jones and Thomae-Forgues, 1984; Lindblom-Ylänne et al., 1996; Burns and Garrett, 2015).

Although there are some overlaps, the specific challenges students might encounter while learning anatomy or histology vary considerably. Most medical students approach anatomy primarily as a memorization task (Miller et al., 2002), a strategy that many have used successfully for college-level courses (Sternberg, 2010). In addition, spatial visualization ability is a helpful asset for learning anatomy (Guillot et al., 2007). However, its impact on overall anatomy learning success appears to be limited in today's learning environment (Sweeney et al., 2014). Students who use a variety of learning strategies that include memorization in combination with higher-level understanding and visualization usually do well in acquiring anatomical knowledge (Pandey and Zimitat, 2006; Ward and Walker, 2008).

In contrast, histology has its own and unique challenges for new learners. Burns and Garrett (2015) recently reported that grades in microscopic anatomy at the University of Arkansas Medical School correlate with preadmission academic variables such as undergraduate grade point average and Medical College Admission Test $\left(\mathrm{MCAT}^{\circledR}\right)$ scores, as well as National Board of Medical Examiners $\left(\mathrm{NBME}^{\circledR}\right)$ Step 1 Examination failures (Burns and Garrett, 2015). Considering that the visual analysis and interpretation of twodimensional images at the microscopic scale and the reconstruction into three-dimensional structures, which reflect the functionality of specific tissues or organs, are central to any histology instruction, this should not be surprising. This approach to histology constitutes a multistep, complex learning process (Notzer and Aronson, 1979) that requires more than the memorization of molecular and cellular information or of histological images and therefore presents a new challenge for many students. In addition, for a beginning learner, visual-spatial cognitive abilities are an important asset for succeeding in a histology course (Helle et al., 2010).

Many medical anatomy and histology components only involve the first year of medical or dental school and the overall hours of anatomy and histology instructions have declined over the last decades (Drake et al., 2009, 2014). This makes the early identification of struggling students and the implementation of supportive interventions to improve the learning outcome of underperforming students a difficult and time-sensitive task.

\section{EXPERIENCES WITH AN INTEGRATED MEDICAL CURRICULUM AT THE UNIVERSITY OF MICHIGAN MEDICAL SCHOOL}

An integrated medical curriculum was first introduced at the University of Michigan Medical School (UMMS) for the 2003-2004 academic year. Since that time, anatomy and histology have been taught at the UMMS in eight organ systembased courses (heretofore called "sequences") starting in September through the middle of March during the first of a four-year long medical program. Each organ system-based sequence is between two to four weeks long (Fig. 1).

At the UMMS, an initial overview of an anatomical region is provided in lecture form at the beginning of each organ system-based sequence. This is later followed by a brief quiz to ascertain students' comprehension of the material and a small group discussion to prepare students for the laboratory assignments. Plastinated specimens and prosections are available for orientation to all students at the beginning of every anatomy laboratory session. Whole body dissections are performed under faculty supervision by small groups of students.

Histology is taught using a combination of traditional teaching methods (lectures, faculty-guided laboratory 


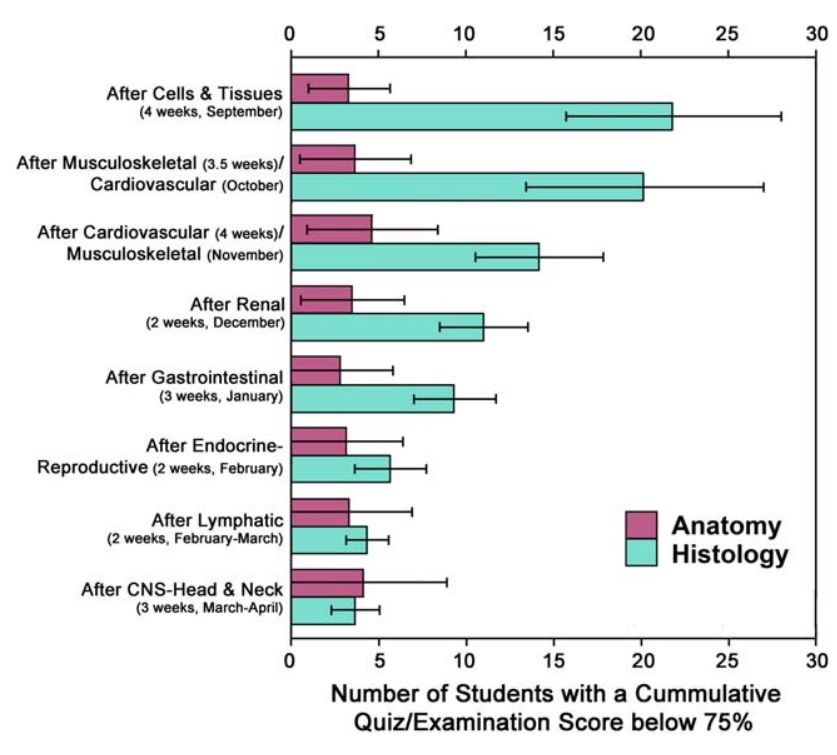

Figure 1.

Number of first year medical students at the UMMS with a failing cumulative quiz/exam score (below $75 \%$ ) for anatomy and histology quiz and examination questions after each of the eight organ-system-based sequences in which these subjects were taught. Results from remediation examinations were not considered for this analysis. BSARB intervention for anatomy and histology usually starts at the beginning of the renal sequence. The columns and bars represent the average and standard deviation calculated from six different M1 classes at the UMMS (matriculating classes of 2007-2012). Each class had between 164 and 171 students. The different organ-based sequences containing an anatomy and histology component are depicted top to bottom in the temporal order in which they are taught in the UMMS first year curriculum. The length of each sequence is indicated on the left side. Only in the academic years 2007-2008 and 2008-2009 the musculoskeletal sequence was taught before the cardiovascular sequence. Starting with the academic year 20092010 the cardiovascular sequence preceded the musculoskeletal sequence.

sessions, demonstration light microscope stations, etc) and electronic learning tools (online lecture videos, virtual microscopy, a course website, supplemental PowerPoint files, etc). A more detailed description of the UMMS histology component was recently published by Holaday et al. (2013). Depending on the organ system-based sequence, 5-23 faculty contact hours (including 1-5 laboratory sessions) are usually scheduled for gross anatomy and 4-16 faculty contact hours (including 1-4 laboratory sessions) for histology.

Learning success is assessed by online multiple-choice weekly quizzes and sequence-ending examinations that contain both anatomy and histology questions, interspersed among other questions specific to that organ system. In addition, anatomy knowledge is also tested by eight laboratory examinations. Histology does not use separate practical examinations, but some questions in the online quizzes and final examinations require the analysis of virtual histology slides. To pass a specific organ-based sequence, a student needs to attain a strictly enforced overall cumulative minimum score of $75 \%$. Cumulative scores below $75 \%$ require remedial work encompassing the entire content of the failed sequence. A final $75 \%$ minimum cumulative score is also expected for several longitudinal disciplines-physiology, biochemistry, pathology, anatomy, and histology. No formal remedial action is mandated if a student's score remains below this threshold for a longitudinal discipline at the end of the first year. As students meeting with the anatomy/histology component director often ask about the consequences of staying below $75 \%$ in an anatomical science subject, this policy does not appear to be widely known among UMMS students and we have no indication that it plays an important role in students' motivation to learn the anatomical sciences. The medical school has implemented several strategies that are outlined below to support students at risk of being below competency in these areas.

Figure 1 shows how University of Michigan medical students adapt to the different learning challenges posed by anatomy and histology. It depicts the number of students with a cumulative examination score for either anatomy or histology under the $75 \%$ mark after each of the eight organ system-based sequences with an anatomy and histology component. Few first-year medical students have difficulties to adjusting immediately to the demands of a medical school level anatomy course. In our experience, students who struggle with anatomy often have additional academic difficulties in other areas. In contrast, about $10-15 \%$ of students initially struggle with histology and have cumulative examination scores below the expected $75 \%$ mark (Fig. 1). This observed difference between students' adaptation to learning anatomy versus histology probably has multiple reasons. Not only have few students been exposed to histology prior to entering medical school (Selvig et al., 2015), but the microscopic scale of cells and tissues, as well as the challenge of identifying them in a complex context, poses initial problems for some students which they do not encounter learning macroscopic anatomy. In addition, UMMS histology quiz and examination questions usually involve images that were not previously available to students and often require the analytical skill of interpreting histological images and linking them to functional facts and physiological processes. With time and often with supportive didactic interventions as described in the next section, most students eventually find a successful learning strategy and develop the skills to do well in both the anatomical sciences and subsequently in the $\mathrm{NBME}^{\circledR}$ Step 1 Examination (Fig. 1 and Table 1).

\section{Supporting Students Struggling with Anatomy or Histology Using a Combination of Academic Review Board Supervision and Individual Counseling}

The experiences over the last 10 years at the UMMS of how to adapt anatomy and histology into an integrated curriculum and to support students struggling in these disciplines might be helpful for other educational programs with a similar curricular structure. At the UMMS, the responsibility of identifying students who are struggling or are at academic risk of failing mainly falls to three entities, the Basic Science Academic Review Board (BSARB), the directors for anatomy and histology disciplines, and the learning support team in the Student Services Unit. As organ-based sequences only last between two to four weeks, sequence directors often have difficulty identifying students who are struggling with a specific subject or with the material in general.

The BSARB is charged with tracking the academic performance of every student in the preclinical curricular years (approximately 170 students in each UMMS class). The BSARB consists of seven voting and 17 nonvoting members, comprised of school administration representatives, curricular 
Quantitative Analysis of Students that were Identified by the Basic Science Academic Review Board (BSARB), Because of Deficiencies in Histology and their Subsequent Success in Passing the NBME ${ }^{\circledR}$ Step 1 Examination

\begin{tabular}{|c|c|c|c|c|}
\hline & \multicolumn{4}{|c|}{ Matriculation Year } \\
\hline & 2010 & 2011 & 2012 & 2013 \\
\hline $\begin{array}{l}\text { Number of UMMS students who completed the M1 } \\
\text { histology component }\end{array}$ & 168 & 167 & 171 & 167 \\
\hline $\begin{array}{l}\text { Number of students contacted by the BSARB because of } \\
\text { deficiencies in histology }\end{array}$ & 24 & 18 & 16 & 13 \\
\hline $\begin{array}{l}\text { Percent of students who met with the histology component } \\
\text { director after being directed to do so by the BSARB }\end{array}$ & $41.7 \%$ & $50 \%$ & $56.3 \%$ & $61.5 \%$ \\
\hline $\begin{array}{l}\text { Percent of students contacted by the BSARB because of } \\
\text { deficiencies in histology who finished the histology } \\
\text { component with a cumulative examination score of }>75 \%\end{array}$ & $83.3 \%$ & $83.3 \%$ & $87.5 \%$ & $84.6 \%$ \\
\hline $\begin{array}{l}\text { Percent of students contacted by the BSARB with } \\
\text { deficiencies in histology who since have passed the NBME } \\
\text { Step } 1 \text { Examination on their first attempt }\end{array}$ & $95.8 \%$ & $94.4 \%$ & $100 \%{ }^{a}$ & $\mathrm{~N} / \mathrm{A}$ \\
\hline
\end{tabular}

${ }^{\text {a }}$ Student who have taken the NBME ${ }^{\circledR}$ Step 1 Examination as of November 2014.

Four students have deferrals to take the examination at a later time.

component directors, class counselors, an academic learning specialist, teaching faculty, and four nonvoting student representatives. The students and most faculty members are elected by their respective constituencies. The BSARB meets on a monthly basis during the entire academic year. If a student receives a failing overall score in one of the organ system-based sequences, the BSARB (on recommendation of the sequence director) will dictate a specific, individualized remediation process. In most cases, remediation will require the passing of a makeup examination that includes all topics and learning objectives for that organ system sequence. If a student fails the makeup examination, the BSARB will request additional remedial coursework over the following summer, or require the student to repeat the sequence the following academic year. In extreme cases, if a student fails multiple sequences, a repeat of part or the entire M1 year could be required.

An equally important contribution in helping students in academic trouble is the support received from the two class counselors, an academic learning specialist, the assistant dean for student services, and the anatomy and histology discipline directors. This team monitors student performances weekly to identify those students who might be struggling before high-stakes examinations occur in each sequence, and before they may be discussed at the BSARB meetings.

By November, after accumulating two to three months of anatomy and histology examination results, the BSARB mandates that students whose cumulative anatomy or histology scores fall below the $75 \%$ expectation line, meet with the anatomy and/or histology discipline director to discuss his/ her study and learning strategy for the subject (if they have not done so already through the weekly monitoring process). Some students also approach the component director(s) prior to any BSARB action and meet with her/him to discuss improvements of their learning strategy. The board may also recommend that a student receive help from a tutor (usually an upper-level medical student) or an evaluation by the academic learning specialist. Although the reasons behind why students struggle with subjects like histology and anatomy vary considerably, there are characteristic study strategies and learning approaches that are common among students either doing well or underperforming in the anatomical sciences (Selvig et al., 2015). As shown in Figure 1, a significant number of first year UMMS students have early difficulties with finding a successful learning approach for histology. The reasons why some students initially struggle with histology often include their academic background, a lack of prior exposure to histology, and deficiencies of using the offered educational resources in their appropriate context (Selvig et al., 2015). Students' attitude to histology as an important part of their professional education is also a strong indicator for their academic success in the UMMS histology component (Selvig et al., 2015). Therefore, specific emphasis is put in the introductory lecture and the individual meetings between students and the component director on the relevance of histology as a basic science subject, its foundational importance for pathology, and as an exercise of the analytical processing of visual data.

Recommendations that are initially presented to struggling students often fall into one or more of the following strategies: (1) using the learning objectives for a more focused learning approach; (2) developing a more directed plan for using the available learning resources; (3) attending lectures in person rather than watching online streamed lecture podcasts; (4) adequately preparing for and taking part in faculty-guided laboratory sessions; and (5) subject-specific test taking skills. These suggestions are often based on learning strategies common to successful histology learners as identified by Selvig et al. (2015). In our experience, such simple advice often has a considerable impact on a student's motivation to learn and on his/her examination performance. A while ago, we started to offer early (before any BSARB action has been taken) 
individual consultations with the component director(s) to students who are dissatisfied with their academic performance in anatomy and/or histology, as well as an extracurricular lecture presentation focusing on strategies how to analyze histological images and the proper use of the offered learning resources. Over the last few years an increasing number of M1 students have taken advantage of these opportunities. Although many students are able to adjust and to catch up to their peers without administrative intervention, in our experience, for some students, the guidance and mandates provided by the BSARB and the advice received from the discipline directors coincides and most likely plays an important supportive part in this process (Fig. 1 and Table 1).

\section{Opportunities and Limitations of the Academic Review Board Approach}

As each student encounters his/her own challenges during the first year of medical school and as higher education learning involves highly variable learning strategies (Newble and Entwistle, 1986), individual solutions need to be offered to students who do not perform to the expected level in a professional anatomy or histology course/component. At the UMMS, the supervisory role of an academic review board in combination with individual counseling has worked well, usually resulting in a marked improvement of a student's examination scores. All students from the matriculation years 2010 to 2012, who were contacted by the BSARB because of deficiencies in histology and have subsequently attempted to take the $\mathrm{NBME}^{\circledR}$ Step 1 Examination, have successfully passed that examination, the majority on their first attempt (Table 1).

However, the following limitations of such an approach need be considered. First, although students start participating in anatomy and histology quizzes and examinations at the beginning of the academic year, it takes about two to three months until the BSARB is able to review enough assessment data to identify underperforming students, and provide mandates to the students to meet with the respective discipline director and implement new learning strategies. If they have not done so previously, struggling students would then meet with the discipline director starting in December close to the halfway point of the M1 anatomy and histology component. This is sometimes delayed further by administrative or student-specific issues, such as hesitancy to contact and meet with the discipline directors (Table 1). Stegers-Jager et al. suggest a possible solution for the latter problem. They report that the threat of academic dismissal significantly improves students' help-seeking behavior without affecting dropout rates or study progress during the first two years of medical school (Stegers-Jager et al., 2011).

Second, while we found that offering voluntary consultation sessions with the subject component director early during the academic year is an effective way to reach many students who initially underperform in the anatomical sciences, some students remain reluctant to seek out help in a timely manner and only do so after receiving repeated letters from the BSARB. We do not have information about the individual reasons for why each student chose (or did not choose) to seek help, nor do we have information on how the student perceived the value of the described supervision and remediation strategy. While such information might be interesting, it would likely provide little additional information about the efficacy of the described procedures we implemented.
Third, an additional limitation of the academic review board strategy is its reliance on examination results in identifying underperforming students. Although passing the relevant course or sequence examinations and later doing well in the $\mathrm{NBME}^{\circledR}$ Step 1 Examination is usually considered strong evidence that a student has mastered the relevant preclinical material, higher level learning abilities such as pattern recognition, teamwork, and communication skills, as well as synthetic and logical deduction capabilities are not as easily tested in quizzes and examinations.

It needs to be pointed out that this short communication does not provide a quantitative scientific analysis of the proposed remediation procedure's or its individual components' impact on students' learning success in the anatomical sciences. Many students are able to adapt their learning approach to anatomy and histology without outside help. In addition, other types of interventions, changes in teaching strategy, and didactic resources may also be effective in supporting students with academic problems (Tekian and Hruska, 2004; Daly, 2010; Stegers-Jager et al., 2013; Prunuske and Skildum, 2014). The proposed strategy of using an academic review board in combination with individual consultations rather presents an educational case study that has been successfully used at the UMMS (Table 1). Finally, while mandated meetings and consultations can provide students with helpful information to improve their learning and study strategies, understanding the variable incorporation of those strategies by each student is a complex phenomenon, requiring more specific understanding of learners' motivation and learning preferences.

\section{CONCLUSIONS}

As longitudinal disciplines, anatomy and histology are at risk of becoming fractionated in an integrated medical or dental curriculum, loosing their didactic continuity. In addition, both anatomy and histology have specific challenges for individual learners, who might therefore be at risk of failing to achieve competence in these subjects. Continuous academic review and timely supportive intervention appear to be helpful in identifying such students and in finding individual solutions that will help them to develop their own, successful learning strategy to pass an anatomy/histology course or component, or to remediate a failing performance.

\section{ACKNOWLEDGMENTS}

Special thanks belongs to our anatomy and histology teaching colleagues, and also to Tamara Stein, the anatomy discipline director and assistant director of the first year of the UMMS curriculum, and Dr. Roger Grekin, the overall director of the first two years of the curriculum. Their work with the University of Michigan medical students is pivotal for the success of the strategy described in this manuscript. Tamara Stein's comments and suggestions for this manuscript were also very helpful. The contributions made by Brenda Chism, Karri Grob, Crystal Napier, and Nikki Zaidi of compiling the data displayed in Figure 1 and Table 1 are much appreciated.

\section{NOTES ON CONTRIBUTORS}

MICHAEL HORTSCH, Ph.D., is an associate professor in the Departments of Cell and Developmental Biology and of Learning Health Sciences at the University of Michigan in Ann Arbor, Michigan. Since 1991 he has taught medical and 
dental histology and currently is the coordinator of the M1 histology component at the UMMS. In 2012 he received the Kaiser Permanente Award for Excellence in Preclinical Teaching from the UMMS and in 2013 he was the winner of a University of Michigan Provost's Teaching Innovation Prize.

RAJESH S. MANGRULKAR, M.D., is Associate Dean for Medical Student Education and associate professor in the Departments of Internal Medicine and of Learning Health Sciences at the UMMS in Ann Arbor, Michigan. In addition to his oversight of the curriculum and the student services unit, he actively teaches medical decision-making in the first three years of medical school. In 2010 he was the recipient of the Kaiser Permanente Award for Excellence in Clinical Teaching from the UMMS and the winner of a University of Michigan Provost's Teaching Innovation Prize.

\section{LITERATURE CITED}

Abali EE, Osheroff N, Buxbaum E, Niederhoffer EC, Symes K, Sanders M 2014. Evolving role of the basic science course director in an integrated curriculum. Med Sci Educ 24:349-351.

Audetat MC, Laurin S, Dory V. 2013. Remediation for struggling learners: Putting an end to 'more of the same'. Med Educ 47:230-231.

Bearman M, Molloy E, Ajjawi R, Keating J. 2013. 'Is there a Plan B?': Clinical educators supporting underperforming students in practice settings. Teach High Educ 18:531-544.

Burns ER, Garrett J. 2015. Student failures on first-year medical basic science courses and the USMLE Step 1: A retrospective study over a 20-year period. Anat Sci Educ (in press; doi: 10.1002/ase.1462).

Cleland J, Leggett H, Sandars J, Costa MJ, Patel R, Moffat M. 2013. The remediation challenge: Theoretical and methodological insights from a systematic review. Med Educ 47:242-251.

Cooke M, Irby DM, Sullivan W, Ludmerer KM. 2006. American medical education 100 years after the Flexner report. N Engl J Med 355:1339-1344.

Coppus SF, Emparanza JI, Hadley J, Kulier R, Weinbrenner S, Arvanitis TN, Burls A, Cabello JB, Decsi T, Horvath AR, Kaczor M, Zanrei G, Pierer K, Stawiarz K, Kunz R, Mol BW, Khan KS. 2007. A clinically integrated curriculum in evidence-based medicine for just-in-time learning through on-the-job training: The EU-EBM project. BMC Med Educ 7:46.

Daly FJ. 2010. Use of electronic anatomy practical examinations for remediating "at risk" students. Anat Sci Educ 3:46-49.

Donner RS, Bickley H. 1993. Problem-based learning in American medicaleducation: An overview. Bull Med Libr Assoc 81:294-298.

Drake RL. 1998. Anatomy education in a changing medical curriculum. Anat Rec 253:28-31.

Drake RL, Lowrie DJ Jr., Prewitt CM. 2002. Survey of gross anatomy, microscopic anatomy, neuroscience, and embryology courses in medical school curricula in the United States. Anat Rec 269:118-122.

Drake RL, McBride JM, Lachman N, Pawlina W. 2009. Medical education in the anatomical sciences: The winds of change continue to blow. Anat Sci Educ 2:253-259

Drake RL, McBride JM, Pawlina W. 2014. An update on the status of anatomical sciences education in United States medical schools. Anat Sci Educ 7:321325 .

Durning SJ, Cleary TJ, Sandars J, Hemmer P, Kokotailo P, Artino AR. 2011 Perspective: Viewing "strugglers" through a different lens: How a selfregulated learning perspective can help medical educators with assessment and remediation. Acad Med 86:488-495.

Forester JP, McWhorter DL, Cole MA. 2002. The relationship between premedical coursework in gross anatomy and histology and medical school performance in gross anatomy and histology. Clin Anat 15:160-164.

Guillot A, Champely S, Batier C, Thiriet P, Collet C. 2007. Relationship between spatial abilities, mental rotation and functional anatomy learning. Adv Health Sci Educ Theory Pract 12:491-507.

Hauer KE, Ciccone A, Henzel TR, Katsufrakis P, Miller SH, Norcross WA, Papadakis MA, Irby DM. 2009. Remediation of the deficiencies of physicians across the continuum from medical school to practice: A thematic review of the literature. Acad Med 84:1822-1832.

Helle L, Nivala M, Kronqvist P, Ericsson KA, Lehtinen E. 2010. Do prior knowledge, personality and visual perceptual ability predict student performance in microscopic pathology? Med Educ 44:621-629.

Heylings DJ. 2002. Anatomy 1999-2000: The curriculum, who teaches it and how? Med Educ 36:702-710.
Holaday L, Selvig D, Purkiss J, Hortsch M. 2013. Preference of interactive electronic versus traditional histology learning resources by University of Michigan medical students during the first year histology component. Med Sci Educ 23:607-619.

Huff KL, Fang D. 1999. When are students most at risk of encountering academic difficulty? A study of the 1992 matriculants to U.S. medical schools. Acad Med 74:453-460.

Jones RF, Thomae-Forgues M. 1984. Validity of the MCAT in predicting performance in the first two years of medical school. J Med Educ 59:455-464.

Klement BJ, Paulsen DF, Wineski LE. 2011. Anatomy as the backbone of an integrated first year medical curriculum: Design and implementation. Anat Sci Educ 4:157-169.

Koenig JA. 1992. Comparison of medical school performances and career plans of students with broad and with science-focused premedical preparation. Acad Med 67:191-196.

Lindblom-Ylänne S, Lonka K, Leskinen E. 1996. What predicts success during basic science studies? A cognitive approach. High Educ 31:507-527.

McKeown PP, Heylings DJ, Stevenson M, McKelvey KJ, Nixon JR, McCluskey DR. 2003. The impact of curricular change on medical students' knowledge of anatomy. Med Educ 37:954-961.

McLaughlin K, Veale P, McIlwrick J, de Groot J, Wright B. 2013. A practical approach to mentoring students with repeated performance deficiencies. BMC Med Educ 13:56.

Miller SA, Perrotti W, Silverthorn DU, Dalley AF, Rarey KE. 2002. From college to clinic: Reasoning over memorization is key for understanding anatomy. Anat Rec 269:69-80.

Muller JH, Jain S, Loeser H, Irby DM. 2008. Lessons learned about integrating a medical school curriculum: Perceptions of students, faculty and curriculum leaders. Med Educ 42:778-785.

Newble DI, Entwistle NJ. 1986. Learning styles and approaches: Implications for medical education. Med Educ 20:162-175.

Notzer N, Aronson M. 1979. Differential evaluation of students' performance in histology. All questions are equal but some are more equal than others. Med Educ 13:79-81.

Older J. 2004. Anatomy: A must for teaching the next generation. Surgeon 2: 79-90.

Pandey P, Zimitat C. 2006. Medical students' learning of anatomy: Memorisation, understanding and visualisation. Med Educ 41:7-14.

Pell G, Fuller R, Homer M, Roberts T. 2012. Is short-term remediation after OSCE failure sustained? A retrospective analysis of the longitudinal attainment of underperforming students in OSCE assessments. Med Teach 34:146-150.

Prunuske A, Skildum A. 2014. Just-in-time remediation of medical students during the preclinical years. Med Sci Educ 24:103-109.

Royal KD, Kernick ET, Gilliland KO. 2014. Are repeat exam scores trustworthy? A note about measurement error and the need for genuine instructional remediation. Med Sci Educ 24:39-41.

Sadik A, Rojas L. 2014. How to identify at-risk medical students based on learning style, personality indicator, and learning strategy tests-A mixed method for a pilot study. Med Sci Educ 24:111-115.

Scheffer C, Tauschel D, Neumann M, Lutz G, Cysarz D, Heusser P, Edelhäuser F. 2012. Integrative medical education: Educational strategies and preliminary evaluation of the Integrated Curriculum for Anthroposophic Medicine (ICURAM). Patient Educ Couns 89:447-454.

Selvig D, Holaday LW, Purkiss J, Hortsch M. 2015. Correlating students' educational background, study habits, and resource usage with learning success in medical histology. Anat Sci Educ 8:1-11.

Stegers-Jager KM, Cohen-Schotanus J, Splinter TA, Themmen AP. 2011. Academic dismissal policy for medical students: Effect on study progress and helpseeking behaviour. Med Educ 45:987-994.

Stegers-Jager KM, Cohen-Schotanus J, Themmen AP. 2013. The effect of a short integrated study skills programme for first-year medical students at risk of failure: A randomised controlled trial. Med Teach 35:120-126.

Sternberg RJ. 2010. Teach creativity, not memorization. Chron High Educ 57: A29.

Sweeney K, Hayes JA, Chiavaroli N. 2014. Does spatial ability help the learning of anatomy in a biomedical science course? Anat Sci Educ 7:289-294.

Tekian A, Hruska L. 2004. A review of medical school records to investigate the effectiveness of enrichment programs for "at risk" students. Teach Learn Med 16:28-33.

Ward PJ, Walker JJ. 2008. The influence of study methods and knowledge processing on academic success and long-term recall of anatomy learning by first-year veterinary students. Anat Sci Educ 1:68-74.

Winston KA, Van Der Vleuten CP, Scherpbier AJ. 2010. At-risk medical students: Implications of students' voice for the theory and practice of remediation. Med Educ 44:1038-1047.

Winston KA, Van Der Vleuten CP, Scherpbier AJ. 2013. Remediation of atrisk medical students: Theory in action. BMC Med Educ 13:132. 